\title{
El gran pacto social que debería esperar
}

\author{
The great social pact that should await
}

\author{
Belén Cardona Rubert \\ Catedrática de Derecho del Trabajo y la Seguridad Social \\ Universidad Valencia \\ ORCID ID: 0000-0002-9260-6207 \\ Jaime Cabeza Pereiro ${ }^{* *}$ \\ Catedrático Derecho del Trabajo y la Seguridad Social \\ Universidad de Vigo \\ ORCID ID: 0000-0001-8847-3934
}

doi: https://doi.org/10.20318/labos.2021.6050

En abril de 2020 publicamos un breve y esquemático artículo de opinión titulado "Para un gran pacto social" en el que expresábamos unas ideas sobre unos contenidos básicos que debería incluir ese gran pacto que germinara en el marco del diálogo social tripartito. En el inicio de 2021, cuando tan altas expectativas se depositan en la concertación entre las organizaciones sindicales, empresariales y el Gobierno, nos ha parecido oportuno desarrollar un poco más esas ideas. Hemos aceptado con gusto, por lo tanto, la invitación que se nos ha formulado desde esta revista, aunque hemos tenido que actualizar ciertas ideas a causa de la experiencia vivida en los últimos ocho meses y de los acontecimientos sucedidos desde entonces. Las reflexiones que se expresan a continuación no aspiran a conformar una propuesta completa de cambios necesarios, pero sí que son una toma de postura explícita sobre algunos de los problemas y de las insuficiencias más evidentes que, en la actualidad, afectan a nuestro mercado de trabajo.

\section{Compromiso categórico de que la contratación temporal se reconduzca a la media de los Estados de la Unión Europea}

En nuestro marco de relaciones laborales, es muy evidente que la contratación temporal actúa como amortiguador de las crisis de empleo. Quizá haya matices entre diferentes vicisitudes de incremento del desempleo, pero la de 2020 producida por la pandemia resulta muy paradigmática. Entre el cuarto trimestre de 2019 y el tercer trimestre de 2020, de acuerdo con los datos de la EPA, el porcentaje de desempleo creció en casi dos puntos y medio -del 13,78 por 100 al 16,26 por 100-. En ese período, y correlativamente, la tasa de temporalidad se redujo en prácticamente dos puntos -del 26,10 por 100 al 24,17 por 100 - Es decir, y como podía predecirse, los contratos temporales contienen la pérdida de empleo indefinido.

En realidad, esta circunstancia no es exclusiva del sistema español, sino que se repite, con ciertas características especiales, en otros países. A veces es la contratación temporal directa y otras, la que

*maría.b.cardona@uv.es

*Jcabeza@uvigo.es 
se realiza a través de empresas de trabajo temporal. Incluso ciertas reformas que han favorecido una y otra se han diseñado precisamente para que las empresas sortearan con más flexibilidad las épocas recesivas. Lo que sucede es que este "parachoques" es mucho más amplio en España, de modo que, en realidad, no funciona como tal, sino que produce el efecto de pérdida de muchos más puestos de trabajo que en los marcos de comparación que puedan contrastarse. Es decir, cuando el empleo se contrae, se denuncian muchos más contratos de los que sería adecuado extinguir, porque la "flexibilidad de salida" resulta mucho más segura, más expeditiva e incluso más económica que la flexibilidad interna. A lo que habría que ańadir que se produce una amortización de puestos de trabajo "por exceso", acompañándola de otras medidas de reorganización de la actividad con la plantilla restante.

Consecuentemente, el problema del modelo español no está en la debilidad de las medidas de flexibilidad interna, sino en la mayor fortaleza de la "de salida". Sin duda, aquélla debe ser adecuada y mejorada, pero sin que se desatienda el problema fundamental, que se ubica en la excesiva rotación en las personas y en los puestos de trabajo y en la desproporcionada fungibilidad de unas y de otros. A la inversa, cuando el empleo se dilata siempre lo hace a través de un incremento de los porcentajes de temporalidad, sin que hasta ahora se haya podido enderezar esta tendencia perniciosa.

Se han buscado explicaciones basadas en una especie de "singularidad" de nuestro sistema productivo, que produciría mayor temporalidad -aunque, habría que precisar, en todo caso más estacionalidad-, en particular por la cierta sobredimensión del sector servicios en relación con el industrial. La explicación podría ser plausible, o al menos serlo en parte, si no fuera porque otros países, con una estructura de la ocupación similar a la nuestra, exhiben porcentajes de temporalidad más contenidos. Las circunstancias de necesidad temporal de trabajo subordinado obviamente existen, e incluso podría admitirse que en intensidad algo superior que en el caso de otras economías más industrializadas. Pero no explican ese diferencial tan excesivo de porcentajes de contratos temporales que lastra nuestro sistema de relaciones laborales.

Pueden apuntarse otras circunstancias explicativas, asimismo insuficientes en sí mismas. Entre ellas, cabe argüir que los ciclos económicos se han acelerado, de tal forma que recién superada una crisis emerge otra. Lo cual extrema la precaución de las empresas, de modo que el empleo que generan es muy casual, a la espera de que en un futuro inmediato deban destruirlo de nuevo. Lo cual, en el fondo, más que explicativo de la realidad, solo es descriptivo de la misma: como los períodos expansivos se hacen más breves, los comportamientos de los mercados de trabajo se aceleran. De nuevo se trata de un argumento que no resiste comparaciones con el comportamiento del mercado de trabajo en otros países próximos.

Descrito el problema, lo cierto es que se han puesto en marcha medidas normativas de muy diverso tipo para combatirlo, sin que hasta ahora se haya revertido drásticamente la tendencia. En honor a la verdad, algo se ha corregido, desde la "normalidad" de los años 2005-2007 en torno a la tercera parte de la población activa hasta la de finales de 2019, de poco más del 26 por 100. Claro que esta última con una tasa de paro muy superior al 8,6 por 100 existente en 2007 . Es lícito preguntarse cuál sería el porcentaje de temporalidad en un escenario en el que el desempleo descendiera hasta el 8 por 100. En apariencia, y por desgracia, habría que responder que muy próximo a los guarismos de la época previa a la crisis de 2008.

Dichas medidas correctoras son suficientemente conocidas. Por recordar algunas de las más importantes, solo con una breve mención a las mismas, baste la siguiente síntesis:

- Derogación general de los contratos de fomento del empleo, con la excepción del colectivo de personas con diversidad funcional. Ha sido decepcionante que esa supresión no hubiera producido un reajuste a la baja de la temporalidad, cuando su aparición a comienzos de los ańos ochenta del siglo pasado se sitúa en el germen del problema. Los efectos de tal 
derogación han consistido básicamente, en un "corrimiento" hacia los contratos de obra y servicio y eventual, hoy absolutamente predominantes.

- Normas de incentivo y desincentivo, consistentes básicamente en subvenciones y bonificaciones y deducciones en las cotizaciones generales a los contratos indefinidos y penalizaciones en las cuotas de los contratos temporales, en particular de muy breve duración. Ya se ha hecho suficiente reflexión sobre lo poco eficientes que han sido las medidas de incentivo a la contratación indefinida. En cuanto a las penalizaciones por la temporalidad en cotizaciones, sin duda son medidas justificadas, necesarias y proporcionadas, pero su eficacia para contenerla ha sido prácticamente insignificante.

- Reglas de indemnizaciones por extinción de contratos temporales, que han sido normalizadas en su configuración actual a partir de la reforma de 2006. Su capacidad para contener los porcentajes de contratos temporales tampoco parece excesiva, si bien su puesta en marcha progresiva ha coincidido con la crisis de 2008. Con todo, parece razonable mantenerlas como medidas de disminución de la dualidad entre trabajo indefinido y temporal. En realidad, las mayores dudas en relación con ellas se han planteado desde la perspectiva de la cláusula 4 del Acuerdo Marco Europeo sobre el trabajo de duración determinada y del principio de igualdad, aunque han proyectado interrogantes lógicos acerca de la selección de modalidades contractuales exentas de la indemnización por fin de contrato.

- Medidas relativas al encadenamiento de contratos centradas especialmente, y omitiendo una abundante y no siempre coherente doctrina judicial, en la superación de cierto número de meses durante dos o más contratos. Estas medidas no han venido acompańadas de una necesaria e invocada necesidad de que la negociación colectiva pusiese coto a la rotación de varias personas contratadas temporalmente en el mismo puesto de trabajo. En todo caso, y sin que deba cuestionarse su mantenimiento, no han producido tampoco una apreciable incidencia en términos de descenso de los contratos temporales. Lo mismo habrá que predicar de otras próximas, relativas a la impugnación de oficio de las prestaciones de desempleo por parte del SEPE.

- Establecimiento de un término fijo a los contratos de obra o servicio. Ha sido una modificación necesaria introducida en 2010 para evitar desproporcionados abusos que se habían producido, en particular en la Administración pública y en la sucesión de empresas auxiliares en la misma actividad contratada. Aunque sin duda ha sido muy conveniente para normalizar el uso de esta modalidad contractual, no ha servido a otras funcionalidades diferentes. El reciente giro jurisprudencial producido con la STS de 29 diciembre 2020 debería ser un augurio de mejora de la situación y de descenso acusado de la temporalidad. Pero, a la espera de que, poco a poco, se consoliden sus efectos, es previsible un desplazamiento desde el contrato de obra al de acumulación de tareas, que seguramente gane en protagonismo a la vista de esa nueva jurisprudencia unificada.

Por otra parte, la norma ha confiado un buen número de asuntos regulatorios a la negociación colectiva. Es difícil formular un juicio de valor sobre la incidencia de los convenios en el régimen de los contratos temporales, pero debe reconocerse que ha producido un efecto expansivo en la utilización del contrato de obra y en el eventual. Por ejemplo, en la identificación demasiado flexible de obras y servicios con sustantividad propia, o de puestos de trabajo para ser ocupados eventualmente, o en la extensión temporal de los contratos de acumulación de tareas, entre otros asuntos. Pero también es verdad que en no pocas ocasiones ha establecido porcentajes exigentes de contratos indefinidos, o impuesto conversiones de contratos temporales en fijos. Claro que está por hacer una evaluación empírica de la efectividad de estas medidas. Simultáneamente, el papel de la negociación 
colectiva ha sido más bien limitado cuando la norma la ha habilitado explícitamente para poner coto a los contratos temporales. De nuevo, la remisión del art. 15.5 a la misma para evitar la rotación de personas en el mismo puesto es un ejemplo inmejorable.

Asimismo, habría que abordar una perspectiva institucional. Desde ella, podría decirse que no ha sido decisiva, en apariencia, la aportación de las empresas de trabajo temporal. Desde su legalización en 1993 han pasado por diversas vicisitudes normativas que han producido, a la postre, un recurso a las mismas selectivo, restringido sobre todo a empresas usuarias de cierta dimensión. No parece razonable concluir que a día de hoy sean un factor expansivo de la temporalidad, aunque tampoco - pese al discurso que se mantiene desde las mismas- un instrumento de control de una temporalidad indeseable. En un plano parecido, sí que debería achacárseles un impacto nocivo a las empresas multiservicio, producido básicamente por el aprovechamiento masivo que han hecho de la doctrina judicial permisiva con el contrato de obra o servicio para atender a las contratas, ahora aparentemente en trance de superación, como ya ha quedado apuntado.

Mención aparte debe hacerse al sector público como espacio de desproporcionada intensidad del trabajo precario y de duración determinada. Tampoco es fácil en este contexto expresar una explicación convincente, pero sí algunas causas concurrentes, todas ellas derivadas de una defectuosa gestión de la res publica. La mala ordenación y planificación de las plantillas, la discrecionalidad en la contratación, las insuficientes ofertas de empleo público producidas por políticas de ajuste, la utilización de técnicas administrativas que confieren competencias impropias a las Administraciones locales, y, en general, el mantenimiento de un empleo estable estructuralmente insuficiente son características del empleo público. Por supuesto, lo mismo habría que expresar, sin apenas matizaciones, en cuanto a las relaciones estatutarias no laborales. Debe ańadirse que hay una inclinación grande al desorden, que magnifica todas las tendencias descritas.

Con todo lo dicho, está comúnmente aceptado que gran parte de la temporalidad es fraudulenta. De modo que habría que preguntarse por los mecanismos de control y por los problemas sistemáticos en corregir el fraude. Sin duda, la Inspección de Trabajo ha desempeñado un papel importante, si bien sobre todo cuando a este asunto se le ha reconocido la importancia que tiene desde los estamentos políticos. En cuanto a los órganos judiciales, su actuación ha sido ambivalente a lo largo de los años, hasta el punto de que sería muy difícil expresar orientaciones muy definidas.

Así descrito el problema, no existen soluciones sencillas ni a corto plazo. Se ha-abogado por una reforma legal que propicie la unificación del contrato de obra y de acumulación de tareas en uno solo, basándose en el refuerzo de la causalidad y la restricción de su uso. Se han planteado incrementos de las indemnizaciones por fin de contrato y una serie de penalizaciones por el recurso excesivo a los contratos temporales. Se ha sugerido la centralización de toda o de parte de la contratación en las empresas de trabajo temporal. Se ha postulado un incremento de las exigencias en torno a la seguridad y la salud en el trabajo. Seguramente, todas estas iniciativas serían dignas de analizarse y la mayoría de ellas resultarían útiles.

Sin embargo, la solución tiene que estar más en el contexto de los grandes pactos de política social. Tiene que trasladarse un mensaje nítido de que la situación actual es inaceptable y producirse un gran compromiso entre las partes sociales de reducción de la temporalidad en al menos diez puntos porcentuales, hasta alcanzar el promedio de los países de la UE. Las autoridades laborales estatales y autonómicas deben establecer la lucha contra la temporalidad fraudulenta como una de sus políticas más importantes e inaplazables. La negociación colectiva ha de establecer como guía fundamental de actuación en esta materia la reducción de los porcentajes de rotación de mano de obra. Y, en términos generales, debe pactarse un calendario exigente y evaluable para alcanzar dicha meta. No debería ser imposible que esta fuera la década de la llegada a la normalidad, pues el año 2030 es una referencia accesible, con un compromiso suficiente de todos los actores. 


\section{Una racionalización del empleo autónomo que confiera seguridad y evite su promoción indiscriminada}

En España existe un porcentaje de trabajo autónomo en relación con la totalidad de la población activa ligeramente superior al de la UE. Pero la diferencia se acrecienta cuando se tiene en cuenta solo el segmento de quienes no emplean a otras personas, donde hay una mayor diferencia con los países de nuestro entorno. Por otra parte, las trabajadoras autónomas, que son proporcionalmente menos que los trabajadores autónomos en términos generales, predominan en el referido segmento, aunque en una pequeña parte ello se explica porque también son proporcionalmente más entre los colaboradores familiares. El asunto tiene gran importancia, porque en ese segmento la precariedad es intensa, o al menos se concentran grandes bolsas de situaciones precarias. Por supuesto que el trabajo autónomo es un macro-concepto que abarca situaciones muy diversas de mayor o menor capacidad decisoria, mayor o menor fortaleza en el mercado y mayor o menor seguridad, pero parece evidente que los perfiles más vulnerables proliferan cada vez más.

Expresado en perspectiva dinámica, es constatable un dato que a primera vista podría interpretarse como de gran estabilidad y podría resultar sorprendente: en noviembre de 2020 había prácticamente el mismo número de personas autónomas de alta que en diciembre de 2019. Según datos del Ministerio de Trabajo y Economía Social, apenas una diferencia de 1.200 a la baja. Ahora bien, este número debe ponerse en entredicho, no en sí mismo, sino como indicador fiable, porque el empleo por cuenta propia es anti-cíclico, pues tiende a incrementarse en épocas en que se pierde empleo por cuenta ajena. Sería bastante arriesgado expresar sin más que las medidas de contención han evitado que se perdiera autoempleo, porque probablemente no ha sido así. Sí que es importante destacar que solo el 20,6 de quienes están de alta en la Seguridad Social por cuenta propia cuentan con personas asalariadas a su cargo.

Por lo tanto, sería necesario valorar la conveniencia y la eficacia de las diversas medidas de apoyo al empleo autónomo y al emprendimiento. Muchas de ellas se destinan a iniciativas de poca viabilidad material, o a altas como personas autónomas de quienes, de una forma u otra, han sido empujadas al empleo por cuenta propia como única alternativa posible. Las medidas de incentivo, además, se han acompañado de una propaganda excesiva y en ocasiones no del todo real en torno a las virtudes de una actividad profesional independiente y a la capacidad de decidir y de elegir que conlleva. Hay que reconocer que esa imagen positiva no solo se proyecta aquí, o incluso en otras realidades se enfatiza más, pero en cualquier caso no se corresponde fielmente con la realidad. No es casual que en la Estrategia Europea para el Empleo el emprendimiento no ocupe el lugar destacado que se le había sido otorgado al principio, en particular en la Cumbre de Luxemburgo. Debería ser un argumento de reflexión para, al menos, evaluar los resultados de una política de fomento de esta forma de trabajar, probablemente para seguir promocionándola, pero de forma más selectiva.

Al mismo tiempo, hay que plantear un debate regulatorio sobre los límites entre el trabajo autónomo y el trabajo subordinado, que suceda en paralelo con un proceso de ajuste de doctrina judicial que se está produciendo, en particular -aunque no exclusivamente- en el contexto de la nueva economía. Parece que solo se suscita este asunto desde una perspectiva de iniciativa legislativa en torno a los riders y a la economía de plataforma, cuando en realidad reviste mayor complejidad. Se trata, sobre todo, de cómo se traza la línea divisoria entre subordinación y autonomía y entre trabajo por cuenta ajena y por cuenta propia. No es cierto que este asunto solo le competa a la jurisprudencia. Aunque las palabras que utiliza el ET en su art. 1.1 no hayan sido objeto de reformas desde 1980, ha habido algún que otro episodio de interferencia legislativa claramente contrario a las orientaciones jurisprudenciales. Por ejemplo, el caso de los transportistas, en el que la política y la 
ideología se impusieron al ordenamiento jurídico, con gran deterioro del sector. $\mathrm{O}$, anteriormente, con ocasión de la Ley del contrato de agencia cuando, socapa de incorporar una Directiva de la Comunidad Económica Europea, se recondujo al ámbito del trabajo autónomo a un gran colectivo de representantes de comercio que ejercían su actividad por cuenta ajena. O, por supuesto, en 2007, cuando se generó el concepto del trabajo autónomo económicamente dependiente, sobre el que enseguida se va a expresar-alguna consideración. En todos estos casos, un programa "liberal" se impuso claramente a otras consideraciones sociales.

La adjetivación como "económica" de la dependencia es, casi siempre, una falsificación, o una contemplación parcial de una relación más amplia. Detrás de la dependencia económica hay ineludiblemente subordinación jurídica, a través de un conjunto de pactos implícitos o explícitos, de colaboración y de control, que no le dejan al trabajador autónomo margen de autonomía alguno. Más bien, el trabajo autónomo económicamente dependiente no es más que una elipsis de lo que materialmente es trabajo dependiente cuya subordinación jurídica no es posible probar suficientemente. Su regulación legal permite que se admitan con naturalidad situaciones tan aparentemente contradictorias como la de trabajo autónomo en los últimos eslabones de la cadena de subcontratación, quizá también aceptada por una especie de contagio de lo que tradicionalmente se ha tolerado, con gran riesgo de la seguridad y de la salud, en el sector de la construcción.

Que en el tercer trimestre de 2020 solo exista la exigua cifra de 8168 TRADES no es sino un dato que hace referencia a las disfuncionales reglas de adquisición de esa condición. Se ha puesto reiteradamente de manifiesto la incongruencia de que exista un número de TRADES absolutamente testimonial en relación con el potencial número de personas -supuestamente- autónomas que reunirían los requisitos del art. 11 del Estatuto del Trabajo Autónomo. Sin embargo, es muy conocida la propuesta originada en círculos bien influyentes de que el mundo de los riders y de la economía de plataforma se convierta en el "reino de los TRADES", con la pretensión evidente de evitarles "males mayores" a algunos grupos de intereses.

La aparición de figuras intermedias entre el trabajo subordinado y el trabajo autónomo ha sido una moda que ha recorrido diversos sistemas de relaciones laborales y que, por sus diferentes manifestaciones, no resulta fácil de evaluar. Pero, en términos generales, aquellos que se han mantenido fieles a un sistema binario producen a la postre mayor seguridad jurídica y menor conflictividad. Desde luego, han sido, además, mucho más eficaces a la hora de perseguir el fraude de ley. Un dato significativo que debe traerse a colación es el del correlativo descenso del número de TRADES al incremento de la actividad de la Inspección de Trabajo en la lucha contra la realidad de los falsos autónomos. Que ha habido una relación causa-efecto en esa campaña intensificada en 2019 ha sido absolutamente notorio. Puede concluirse que los TRADES solo aportan confusión al sistema español de relaciones laborales.

Las propuestas reformadoras deben centrarse, por consiguiente, en una doble operación, de eliminar por una parte el TRADE como concepto específico del trabajo autónomo y, por otra, reforzar la presunción de laboralidad. Este refuerzo podría abordarse de forma selectiva, para ciertos colectivos especialmente necesitados de la misma por las especiales dificultades probatorias que pueden concurrir -vg., trabajo de plataformas o trabajo a distancia- entre otras categorías, o a través de una reforma de la legislación laboral más estructural, que seguramente habría de hacer hincapié en la capacidad de las personas de actuar de forma independiente y con capacidad de negociación en el mercado. Esta segunda propuesta expresa la necesidad implícita de volver la mirada más hacia la ajenidad como criterio determinante. En realidad, una y otra no son incompatibles entre ellas. En todo caso, deberían ir acompañadas de un compromiso de las partes sociales sobre la evitación de conductas abusivas, como se han visto con demasiada frecuencia, por ejemplo, en el ámbito de la economía social. 


\section{Unas reglas equitativas de competencia entre empresas}

Sin duda, cuando se alude a derogar la reforma laboral de 2012, se piensa antes que nada en las reglas sobre concurrencia entre los convenios de sector y los de empresa y en los mandatos sobre ultra-actividad del convenio. Dando por supuesta la vuelta atrás en cuanto a estos últimos, sobre los que, en apariencia, hay un consenso de base sobre los perniciosos efectos que ha producido para ambas partes la regla dispositiva del art. 86.3 ET en su versión actualmente vigente, el asunto más discutido se centra en el art. 84.2. Se produce una excesiva impostación de las diferencias entre la preferencia por un convenio de sector y uno de empresa que, en el imaginario teórico es, en realidad, una disputa entre la ordenación de la negociación colectiva desde el convenio estatal de sector o la disgregación de la misma en las unidades empresariales.

Habría que plantear un reto previo, relativo a las reglas sobre legitimación para negociar. Al margen de otros asuntos menores, pero también de interés -vg., la eliminación de la legitimación "corporativa" del sindicato elegido ad hoc para el convenio de franja- la postergación de las pequeñas empresas en cuanto al cálculo de la legitimación de las organizaciones empresariales es un asunto que tiene gran relevancia en el equilibrio de intereses de nuestro marco de negociación colectiva. Sin duda, la configuración de las unidades de negociación está lastrada por ese desplazamiento de posiciones correlativas en favor de las grandes empresas, tradicional hace ańos en nuestra legislación laboral y acentuado con la reforma de 2011. Consecuentemente, una primera e importante preocupación debería ser una reforma que, a este respecto, resultase más equitativa con la pequeña empresa y permitiese una mayor influencia suya en la estructura negocial y en el contenido de los convenios. En efecto, mucho se ha reflexionado sobre la adaptación de la normativa laboral a este segmento de entidades productivas, pero casi siempre desde la perspectiva de una normativa legal menos protectora de las personas trabajadoras específicamente concebida para ellas. Pero no parece oportuno, ni justificado, ni proporcionado abordar una tarea de ese tipo sin antes emprender una reforma de la negociación colectiva más equitativa y favorable para ellas.

Este asunto, relativo a los criterios de medición de la legitimación, de la constitución de la comisión negociadora y de adopción de acuerdos -que si considerando el número de empresas afiliadas, el número de personas ocupadas, o ambos criterios- está realmente entrelazado con el de la preferencia por un convenio u otro. Las reglas vigentes promueven, como se ha dicho reiteradamente, una disgregación de los ámbitos en favor del convenio de empresa, al menos en cuanto a ciertos contenidos especialmente importantes. Contextualizando su impacto, y sin dejar de reconocer que la realidad es algo más compleja, puede decirse que se ha acogido al art. 84.2 un tipo de empresa caracterizado por tener cierta dimensión y por perseguir una cierta posición competitiva mediante unas condiciones de trabajo más laxas o menos favorables para la parte social. O, por expresar la idea en otros términos, podría decirse que las mismas empresas favorecidas por las reglas de legitimación de los art. 87 y 88 lo son también por la del art. 84.2. Es evidente que aquéllas sin suficiente entidad como para negociar y disponer de un convenio colectivo de ámbito empresarial son las grandes postergadas. Las mismas sobre las que tanto se protesta en el lenguaje político sobre la necesidad de protegerlas. Las mismas para las cuales no es transitable el procedimiento de descuelgue del art. 82.3 ET.

Desde la perspectiva sindical, se ha perseguido con excesiva intensidad, al menos desde el sindicalismo confederal más representativo de nivel estatal, una ordenación de la negociación colectiva conformada a partir del convenio estatal que, a la postre, y vistas las diferentes experiencias sectoriales, debe calificarse como demasiado centralista y poco adaptada a las realidades territoriales. El elenco de materias sobre las que se ha reservado preferencia aplicativa al convenio estatal de sector ha sido, indudablemente, expansivo de más, en detrimento de los ámbitos intermedios de la negociación colectiva. Quizá esta inclinación ha tenido algo de reactiva a la vista de la reforma de 2012, 
pero ya se apreciaba con anterioridad, a su vez como réplica a los "excesos" de la reforma de 1994 y con base en la disciplina interna de las estructuras descentralizadas de esas mismas confederaciones sindicales estatales. Pero no es conveniente, en términos de equidad y de desarrollo económico de ciertos ámbitos territoriales periféricos.

Lo que se postula aquí, en consecuencia, es cierto retorno a los ámbitos sectoriales intermedios. El asunto de los marcos autonómicos de relaciones laborales, tan aplaudido como denostado, y ahora tan ficticiamente amparado por el art. 84.3 ET, no ha sido sino una simplificación de un concepto de más entidad: la conveniencia de apuntalar unidades de negociación en las que confronten sus intereses sindicatos dotados de representatividad con organizaciones empresariales realmente representativas de las empresas radicadas en los territorios. Quizá la fórmula de la reforma de 1994 no haya sido adecuada y seguramente sea necesario combinar capacidad ordenancista de la negociación colectiva en favor de las partes sociales con protagonismo suficiente de los referidos ámbitos intermedios. A tal efecto, quizá pudiera pensarse en adaptar conceptos ya existentes, por ejemplo, planteando descuelgues en ámbitos funcionales supraempresariales y territoriales descentralizados de las reglas de un convenio estatal de sector. $\mathrm{O}$ en exceptuar ciertos contenidos de la prioridad aplicativa del convenio determinado por los instrumentos del art. 83.2 ET, al modo de como lo hace el art. 84.2, pero no en favor de convenios de empresa, sino provinciales o autonómicos de sector. Las fórmulas jurídicas son lo de menos, lo importante es producir un marco legal más equitativo con las empresas y que, al mismo tiempo, produzca una suficiente garantía de representatividad sindical en las mesas de negociación.

Mención aparte merece el problema de las condiciones de trabajo en las empresas auxiliares, un asunto muy relacionado con el anterior. $\mathrm{Al}$ respecto, ha habido iniciativas de reforma legal del art. 42 ET suficientemente conocidas y centradas en una idea más o menos difusa de equiparación retributiva y de otras condiciones laborales entre empresas principales y contratistas o subcontratistas. Parece evidente que esas iniciativas, así planteadas, tienen unos efectos bastante inconvenientes, al menos en términos de aplicación general y sin realizar distinciones en atención al sector de que se trate o a las características de la empresa principal, así como del convenio colectivo aplicable en ésta.

En realidad, el problema acuciante se sitúa en el más reducido contexto de las empresas multiservicios. Aquellas cuya relación con el convenio colectivo aplicable ha sido particularmente problemática, ya sea por aplicación de un convenio colectivo de sector y la selección de cuál, ya por la aplicación de un convenio de empresa negociado al amparo del art. 84.2 ET. Incluso se han planteado alternativas desde los convenios de sector para evitar una competencia más o menos perniciosa provocada por la no aplicación de los mismos. Por otra parte, se ha puesto de manifiesto con reiteración la proximidad del servicio que ofrecen con el de las empresas de trabajo temporal, como se pone de relieve, además, por su relación más o menos problemática con el tópico de la cesión ilegal del art. 43 ET. Sobre ellas sí que se hace necesario legislar, para evitar ciertas prácticas de devaluación de las condiciones de trabajo más o menos frecuentes. Sin duda, la normativa sobre las empresas de trabajo temporal puede servir de modelo, máxime teniendo en cuenta la doctrina del Tribunal de Justicia de la Unión Europea, que ha interpretado en términos relativamente expansivos el ámbito de aplicación de la Directiva 2008/104/CE. Incluso una contemplación de la realidad de estas entidades, que muchas veces se asocian con empresas de trabajo temporal que conforman el mismo grupo corporativo, aconseja cierta aproximación normativa, que podría partir de-puestas a disposición colectivas de personas trabajadoras con cierta estructura organizativa entre ellas. Es decir, se trataría de puestas a disposición especiales, en las que probablemente sería adecuado matizar algo la aplicación del principio de igualdad mediante la negociación colectiva sectorial -entendién- 
dose por tal la que se produciría en el ámbito de las propias empresas multiservicios- con arreglo al art. 5.3 de dicha Directiva. Con este equilibrio de intereses, se garantizaría sólidamente la igualdad entre las condiciones de trabajo de la empresa cliente y de la empresa auxiliar, pero con un margen de adaptabilidad suficiente conferido al convenio de sector que evitaría rigideces excesivas.

Con esta pequeña reforma no se abordaría un problema de solución más compleja, como es el de las condiciones de trabajo en las empresas auxiliares y las responsabilidades que debieran recaer sobre tas empresas principales. Pero seguramente las respuestas al mismo hay que abordarlas descomponiendo la cuestión en asuntos más particulares, porque el tópico de la descentralización productiva reviste una complejidad muy extensa. Que nuestro marco organizativo y de relaciones laborales recurre a distintas modalidades de subcontratación con mayor intensidad que otros sistemas en los que la empresa principal conserva generalmente las diferentes fases del proceso productivo es evidente. Sin embargo, la respuesta a esta realidad no es sencilla y ni siquiera ha de venir fundamentalmente desde el ámbito jurídico laboral.

\section{Una evolución justa de las rentas salariales}

Sobre la materia retributiva, hay dos debates prácticamente entrelazados: de una parte, la congelación del SMI, o al menos el aplazamiento de su subida. De otra, la renovación del Acuerdo para el Empleo y la Negociación Colectiva. Como van a tratarse en el marco del diálogo social de forma simultánea, la interferencia entre ambos es inevitable. La situación que se ha producido con la crisis derivada de la pandemia se puede describir en términos de ralentización en la renovación de los convenios colectivos y de rebaja de los incrementos salariales allá donde se ha llegado a acuerdo entre las partes. Indudablemente, las consecuencias de la COVID-19 en términos de impacto económico son inmensas y la moderación salarial aparece como una respuesta obligada. Ahora bien, debe contextualizarse la situación para otorgar un significado concreto al significante "moderación".

Realmente, la polémica en torno a la congelación o subida del SMI en un 0'9 por 100 tiene más de juego de poder que de otra cosa, a la vista de los limitados efectos de ese magro incremento. Aislada del contexto político, es difícil de entender ese incremento en el empleo público y en las pensiones comparado con la negativa en cuanto al propio SMI. Que se alcance el 60 por 100 del salario medio a final de la legislatura, como objetivo de cumplimiento de la Carta Social Europea, parece bastante accesible. La exigencia se cumpliría automáticamente incrementándolo hoy en día hasta los 1025 euros en 14 pagas. En proyección razonable, se cumpliría para finales de 2023 con un incremento anual del 3,5 por 100 , incluso con una congelación para 2021. Ahora bien, no debe olvidarse que la retribución media española es un 22 por 100 inferior al promedio de los países de la UE.

Los salarios medios en nuestro país son comparativamente reducidos por varios motivos. Las diferencias entre unos sectores y otros ofrecen una explicación parcial, pero insuficiente. Tampoco la estructura productiva interna justifica la diferencia. Parte del problema debe encontrarse en una época de estancamiento retributivo que puede identificarse aproximadamente con el quinquenio entre 2011 y 2016 causado por varios motivos, no solo desde luego por las consecuencias de la reforma laboral de 2012. No se trató únicamente de que los salarios se congelaran, sino que además crecieron las diferencias entre unos sectores y otros, casi siempre en perjuicio del sector servicios en relación con el industrial. Hubo, además, en ese mismo período un fenómeno mucho más acusado, que consistió en una reducción de la participación de los salarios en la renta nacional. Lo cual tiene mayor interés porque en nuestra realidad dicho sector servicios no está precisamente infrarepresentado, y debe considerarse que en él la referida participación se ha incrementado, tanto en España como en cualquier país desarrollado. 
A partir de este haz de consideraciones, no da la impresión de que deba abrirse un nuevo período de estancamiento retributivo, que produciría desde luego muchas consecuencias indeseadas, casi tantas como un incremento inmoderado de los salarios. La evolución del SMI en línea con los compromisos internacionales asumidos es un imperativo categórico. En cuanto a los salarios superiores, no parece conveniente que se produzca un proceso masivo de absorción de salarios negociados colectivamente, sino que éstos deberían crecer en un porcentaje similar, al menos en aquellos sectores en los que, comparativamente, menos hayan subido en la última década. Habiendo sido un porcentaje homogéneo el recomendado en los sucesivos AENC, es llamativo contrastar su impacto real en los distintos sectores. Esta afectación dispar debería considerarse en una evaluación rigurosa de los efectos producidos por los sucesivos acuerdos interconfederales.

Hay convenios colectivos con tablas salariales muy aplanadas en las que puestos de trabajo que requieren un determinado nivel de cualificación se retribuyen con salarios apenas superiores al mínimo interprofesional. La productividad en estos contextos queda muy lastrada por una progresiva desvalorización del trabajo. Es muy necesario evaluar los sectores en los que se producen tales disfunciones, que casi siempre coinciden con aquellos en los que el estancamiento ha sido más acusado a lo largo de las últimas revisiones salariales. Proponer en ellos una excesiva moderación salarial, lejos de ser aconsejable, resultaría totalmente contraproducente a los efectos de una recuperación económica.

En suma, la tarea del AINC no es sencilla, pues sí que hay sectores en donde la moderación salarial sería más aceptable. Pero precisamente coinciden con ámbitos en los que las dinámicas de crecimiento han sido más sostenidas en el tiempo, aunque siempre en una tendencia no muy acusada, como ha sido característica de nuestra negociación colectiva desde ya hace bastantes lustros. Habrá un tiempo de salida de la crisis en el que debería producirse un crecimiento más intenso, que nos aproxime a nuestros vecinos europeos.

Por otra parte, no se ha planteado últimamente desde las organizaciones representativas de los empresarios, o al menos no se ha hecho de forma muy ostentosa, una demanda de rebaja de las cotizaciones. Ciertamente, en España son comparativamente elevadas, al menos por lo que respecta a las que les corresponden a las empresas, aunque solo en términos porcentuales. Ya algo se ha dicho sobre la dinámica evolutiva de los salarios en términos comparativos con Europa. Por otra parte, en el contexto del Pacto de Toledo este tema ha quedado al margen de las más recientes conclusiones. Todo ello no obstante, es un asunto que no pude quedar ausente del debate sobre la evolución de los salarios. Indudablemente, una dinámica de los mismos en términos de moderación no puede llevar aparejado un replanteamiento de los porcentajes de las cuotas patronales. Ahora bien, tendrá que llegar el tiempo de abordar una verdadera convergencia con Europa. El tópico del salario mínimo europeo tiene que ser un escenario bastante adecuado para ello. El horizonte de 2024 puede ser conveniente para plantearse objetivos a medio plazo. Y a tales, efectos de convergencia, a esos sí, desde luego la variante de las cotizaciones debería ser un asunto de consideración.

\section{Una revolución de las políticas activas y pasivas de empleo}

Acaso sea lógico comenzar la reflexión por las políticas pasivas. La experiencia que hemos atravesado, y cuyo fin todavía no se vislumbra claramente, ha puesto en el centro del sistema de protección la prestación por desempleo, muy en particular como respuesta a las suspensiones de contratos y reducciones de jornada tramitadas como ERTES por fuerza mayor o por causas económicas, técnicas, organizativas o de producción, aunque también a causa de las vicisitudes del trabajo fijo-discontinuo. Asimismo, se ha asistido a una utilización masiva, por primera vez, de la prestación por cese de actividad de los tra- 
bajadores autónomos. El SEPE ha sido sometido a unas fuertes tensiones de respuesta a esta situación crítica y las mutuas colaboradoras han lamentado en ocasiones haber asumido el cese de actividad.

Es decir, las prestaciones ligadas a la desocupación involuntaria han sido afectadas desde una perspectiva distinta de la habitual. Tal vez esta experiencia permita plantear conclusiones nuevas que permitan abordar una reforma intensa de unas prestaciones del sistema que, tal y como hoy están legisladas, están muy necesitadas de ciertas dosis de armonización.

Comenzando por lo más obvio: la regulación del ingreso mínimo vital exige repensar y recomponer el nivel asistencial de la protección por desempleo porque se produce una superposición de prestaciones que, en la práctica, resulta redundante e ineficaz. Del mismo modo que es necesaria una remodelación de las medidas de asistencia social de las Comunidades Autónomas, se requiere también una profunda reformulación y debate acerca de la razón de ser y del funcionamiento de dicho nivel asistencial.

En segundo lugar, el nivel contributivo de la prestación debe repensarse, porque funciona a golpe de reformas de distinto tenor que no permiten percibir una identidad clara de modelo de protección. Sin duda, las normas de urgencia de 2020 han sido de respuesta a una situación excepcional, pero obligan a preguntarse si no debe hacerse un esfuerzo mayor en proteger el empleo mediante una cobertura más amplia o menos condicionada de las suspensiones del contrato y reducciones de jornada derivadas de causas empresariales. Por expresar la idea con un símil: si en 2002 se aprobó una normativa de acceso al desempleo vinculada al abaratamiento del despido y que puede calificarse como reforma pro-fraude en el sentido de que levantó cualquier posibilidad de control del mismo en las situaciones legales derivadas del despido, quizá, sin llegar a una intensidad de levantamiento del control sin duda excesiva, podría facilitarse la acreditación del desempleo en caso de suspensión del contrato o reducción de jornada con una intervención administrativa algo menor que hasta ahora. Con todo, de nuevo hay que volver a la clásica pregunta de con qué intensidad debe defenderse activamente el puesto de trabajo. La repuesta, necesariamente, tiene que ser armónica para las diferentes situaciones legales de desempleo.

La reforma de 2002 y alguna de menor entidad -en particular, la de 2013- se plantearon el conocido objetivo de la "activación de la prestación por desempleo", basada en la idea de proteger en particular a la persona en su condición de demandante de empleo, más que de desempleada. Una especie de condicionalidad incipiente en el acceso a la prestación, centrada en el compromiso de actividad, se complementó con una serie de programas de empleo de diversa índole, que se diversificaron bastante en 2013. Por desgracia, al igual que en tantos otros asuntos, no ha trascendido que se haya realizado una evaluación profunda y realista de los mismos.

Entremedias, el debate sobre los mercados de trabajo transicionales popularizado sobre todo con el Libro Verde de 2007 no activó en nuestro sistema, como probablemente debió haberlo hecho, una iniciativa reformadora de la normativa sobre desempleo. Seguramente algunas transiciones de las que se propusieron, máxime teniendo en cuenta la referencia del modelo danés, deberían tener como soporte la prestación por desempleo, y afectar en particular a la identificación de unas nuevas situaciones legales no necesariamente ligadas a la involuntariedad en el cese o suspensión de la relación laboral.

Otro asunto importante se refiere a la intensidad de la protección. Cuando se ha planteado, nuevamente en el corto plazo, el debate en torno a la suficiencia del porcentaje del 50 por 100 de la base reguladora a partir del 181 día de prestación, y cuando se han manipulado por sucesivas reformas las reglas sobre cálculo de la cuantía y duración de la cobertura, es necesaria una reflexión sobre la intensidad adecuada de la protección, atenta desde luego a sus efectos en la vuelta a la actividad por parte de la persona desempleada, pero sin merma de su profesionalidad. Se trata de la conocida dialéctica entre los modelos de work first y de employability, pero sin que deba olvidarse 
que la prestación por desempleo es, antes que nada y por encima de otras consideraciones, una parte central de nuestra Seguridad Social.

Y un defecto de nuestro modelo especialmente disfuncional se refiere al profundo divorcio, tanto en la concepción de la prestación como en su gestión, entre el desempleo y el cese de actividad. Que este último se gestione a través de las mutuas colaboradoras y no a través del SEPE no tiene motivo de fondo alguno que lo justifique, al menos desde una contemplación armónica del sistema de Seguridad Social y de las políticas de empleo. Cuando se concibió el cese de actividad, en 2010, se hizo a imagen de la prestación por desempleo. En el fondo, el riesgo social que afrontan ambas prestaciones es el mismo y la contingencia muy similar. Que se agrande la grieta entre ambas debería evitarse y corregirse. Desde luego, el SEPE es el lugar natural para el reconocimiento y organización de ambas.

Si de verdad se lanza en serio la iniciativa del seguro europeo de desempleo se producirá un contexto muy adecuado para una redefinición del modelo interno, una vez que dicha iniciativa parece mucho más que una simple medida de coordinación al servicio de la libre circulación de trabajadores. El instrumento SURE, de mitigación de los riesgos de desempleo, constituye una experiencia de mutualización del riesgo, cuyo funcionamiento puede, desde luego, condicionar el futuro.

Más perentorio es, si cabe, un rearme de las políticas activas de empleo. Se hace precisa una renovación intensa de la gobernanza del empleo. No se trata tanto de una reformulación de la arquitectura institucional, pero sí de una distinta relación entre los distintos actores y de una mejor coordinación entre ellos. Los problemas competenciales entre el Estado y las CCAA han producido, a la postre, unas políticas activas bastante poco innovadoras y adaptadas a las necesidades actuales, quizá porque ha habido cierto retraimiento a la hora de plantear iniciativas novedosas. Las Administraciones locales no han sido incorporadas materialmente como agentes fundamentales del Sistema Nacional de Empleo. Las partes sociales tampoco han conseguido que el Consejo General desempeñe un papel más constructivo que el de la Conferencia Sectorial. Desde luego, es criticable y contraproducente la separación que se ha producido en departamentos ministeriales entre las políticas activas y pasivas de empleo por un lado y las de formación para el empleo por el otro, separación de la que nada bueno debe esperarse.

Al texto refundido de la Ley de Empleo le falta cierta sustantividad en el enfoque. Es una norma más de organización, procedimiento y planificación que una ley que plantee contenidos concretos. Lo cual podría ser razonable, en un campo en el que las competencias estatales y las autonómicas se solapan, si la legislación autonómica ocupara este espacio, cosa que no ha sucedido. Solo cuando alude a la Estrategia Española de Activación para el Empleo articula unos ejes de actuación, los cuales por cierto deberían ser objeto de revisión y actualización. Por expresar un aspecto muy insuficientemente considerado, el reto de la empleabilidad de las personas debería ser más y mejor abordado, con referencia a recursos y sistemas para preservarla y mejorarla. Haría bien una futura reforma del texto refundido en proponer medidas de actuación que pudieran ser desarrolladas o incluso sustituidas a través de normativa autonómica, para producir cierta adaptación a los territorios de las políticas activas de empleo. Asimismo, una tarea pendiente consiste en reformar desde sus cimientos el sistema de Garantía Juvenil, para abordar uno de los mayores retos que tiene que enfrentar nuestro país, como es el de la integración laboral de las personas jóvenes. Que, afortunadamente, se hayan mejorado los datos tan lamentables al respecto de los años 2013-2014 no quita que deban afinarse los programas, los objetivos y los contenidos del empleo y la empleabilidad juvenil.

En particular, la formación para el empleo es uno de los grandes retos. La mejora de la empleabilidad y de las cualificaciones profesionales de la población activa requieren de una revisión de muchas de las medidas puestas en marcha en los últimos ańos. Más que en el marco normativo diseñado año 2015, el debate debe centrarse en las prioridades formativas, en los contenidos, en 
los colectivos destinatarios y en la provisión de la suficiente cualificación profesional a las personas, con anticipación de los déficits de empleabilidad. Como en otros tantos temas, las divergencias sobre cómo deben gestionarse los fondos finalistas de formación para el empleo han postergado otros asuntos que deberían ser prioritarios. Se trata, en resumen, de un asunto sobre el que debería retornarse al marco del diálogo social bipartito y tripartito.

Otro reto pendiente tiene que referirse a los recursos destinados a las políticas activas de empleo. Sobre él, la Comisión Europea viene insistiendo hace años en la necesidad de fortalecer los servicios públicos de empleo, aunque con poca respuesta. Si la pandemia ha dejado al descubierto la muy deficiente plantilla del SEPE, otro tanto habría que expresar del personal dependiente de las CCAA y dedicado a las políticas activas de empleo. La iniciativa privada, con o sin ánimo de lucro, no ha suplico suficientemente estos déficits, con el añadido de que la colaboración entre ambos entramados, el público y el privado, es manifiestamente mejorable. Sin duda, la época de recuperación que tiene que venir requiere unos servicios públicos adecuados y suficientes, de los que es necesario dotarse, así como de una adecuada colaboración entre éstos y las agencias privadas de empleo, incluyéndose en estas las empresas de trabajo temporal.

A partir de estas ideas generales debería venir la letra pequeña, esto es, las iniciativas concretas. Para que sean eficientes, se requiere atención individualizada de las personas demandantes de empleo, itinerarios personalizados, seguimiento y evaluación particular. La experiencia de las políticas de empleo está cuajada de buenas prácticas y de medidas interesantes que podrían desarrollarse. Por consiguiente, al margen de los problemas de diseño y ejecución de iniciativas de empleo y empleabilidad, los retos se deben dirigir a generar unas estructuras suficientes, capaces de atender y guiar a las personas en sus itinerarios profesionales y en su proceso de integración y de mejora en el mercado de trabajo.

\section{Síntesis}

Este elenco inacabado de tópicos para un diálogo social pone de relieve que hay diversas prioridades. Las que están en la agenda pública más actual son algunas de ellas, pero quizá otras merecieran destacarse más. Se apela a la necesidad de derogar total o parcialmente la reforma de 2012, de elaborar un nuevo Estatuto de los Trabajadores, de actualizar la legislación laboral, o de introducir modificaciones parciales de mejora del mercado de trabajo. Donde hay cierta unanimidad es que el método del diálogo social resulta el más adecuado. Los productos que se hayan de obtener serán diferentes según el marco de juego y los objetivos que se tracen. En todo caso, los temas que se han aludido en este breve comentario configuran, indudablemente, el núcleo de los que deberían debatirse entre las partes sociales y el poder público.

Creemos que las propuestas que se han planteado en estas páginas no deberían generar una disconformidad frontal de las partes sociales, aunque, obviamente, quepan otras alternativas igualmente razonables. Se trata de asuntos sobre los que no es imposible llegar a un amplio acuerdo, o al menos no tanto como en otros en los que las posiciones parecen más difíciles de aproximar. Si se alcanzara, nuestro marco normativo estaría más a la altura de las exigencias de los tiempos actuales en términos de adecuada competitividad de nuestras empresas, pero también de suficiencia de derechos laborales y promoción de la igualdad. 